\title{
Vivências de Familiares de Mulheres com Câncer de Mama: Uma Compreensão Fenomenológica ${ }^{1}$
}

\author{
Daniela Cristina Mucinhato Ambrósio \\ Manoel Antônio dos Santos ${ }^{2}$ \\ Universidade de São Paulo
}

\begin{abstract}
RESUMO - Este estudo teve por objetivo compreender a vivência de familiares de mulheres acometidas pelo câncer de mama em relação à possibilidade de morte, considerando-se o estigma de doença fatal que envolve a doença. Participaram sete filhos, quatro maridos, uma nora e um entrevistado na dupla condição de genro e marido. Foram realizadas entrevistas individuais, ancoradas no referencial fenomenológico, seguindo a questão norteadora: "Como foi, para você, ter um familiar com câncer de mama?". Os resultados demonstraram que a consciência da mortalidade da ente querida se aguça para os familiares, que se percebem como seres-para-a-morte e sentem a necessidade de serem-com-um-profissional-especializado, o que sugere a importância de estender os cuidados à unidade familiar.
\end{abstract}

Palavras-chave: neoplasias da mama; família; morte; Fenomenologia.

\section{Experiences of Family Members of Women with Breast Cancer: A Phenomenological Approach}

\begin{abstract}
The purpose of this study is to understand the experience lived by family members of women with breast cancer regarding their possibility of facing death. Participants were family members of women with cancer: seven children, four husbands, one daughter-in-law and one son-in-law. Individual open interviews were realized, grounded on a phenomenological research framework, according to the following guiding question: "What was it like for you to have a family member with cancer?" The results showed that since the moment of the diagnosis, the consciousness about death of their loved one becomes stronger among the family members, who realize they are beings-towards-death and feel the need to be-with-a-specializedprofessional, which suggests it is important to extend patient care to the family unit.
\end{abstract}

Keywords: breast neoplasms; family; death; Phenomenology.

Segundo o Instituto Nacional de Câncer (INCA), o câncer de mama é o segundo tipo de câncer mais frequente no mundo e o mais comum entre mulheres. Embora seja considerado de bom prognóstico, o câncer de mama é responsável pelos maiores índices de mortalidade feminina no mundo, principalmente na faixa etária entre 40 e 69 anos, com mais de mil mortes por ano. Isso se deve ao fato de que, na maioria dos casos, a doença é diagnosticada em estádios avançados. No Brasil esse tipo de câncer corresponde à segunda neoplasia maligna mais frequente na população feminina, tendo sido estimados 49.240 novos casos para o ano de 2010 (Instituto Nacional do Câncer, 2009).

Historicamente, o câncer é visto como uma doença que leva à morte. Nesse sentido, é revestido por um caráter simbólico que atrela, à sua representação no imaginário coletivo, diversas significações, tais como desordem, catástrofe, castigo

1 Apoio: CNPq; Fundação de Amparo à Pesquisa do Estado de São Paulo - FAPESP; Núcleo de Ensino, Pesquisa e Reabilitação de Mastectomizadas (REMA) da Escola de Enfermagem de Ribeirão Preto da Universidade de São Paulo, em particular a Profa. Dra. Ana Maria de Almeida, coordenadora do serviço, e Maria Antonieta Spinoso Prado, enfermeira assistencial

2 Endereço para correspondência: Faculdade de Filosofia, Ciências e Letras de Ribeirão Preto - USP, Departamento de Psicologia. Av. Bandeirantes, 3900. Ribeirão Preto, SP. CEP 14040-901. Fone: (16) 36023645. -E-mail: masantos@ffclrp.usp.br e fatalidade (Fonseca, 1999; Peres \& Santos, 2009; Tavares \& Trad, 2005; Trincaus \& Côrrea, 2007). De acordo com um estudo realizado por Westman, Bergenmar e Andersson (2006), a vivência do diagnóstico de câncer traz para os pacientes o despertar de reflexões existenciais relacionadas ao sentido da vida e da morte. Viver como uma doença como o câncer de mama é experienciado como necessidade de conviver com uma enfermidade estigmatizante, que desperta sentimentos negativos e preconceitos, o que leva a paciente a ter que se deparar constantemente com incertezas (Almeida, Mamede, Panobianco, Prado \& Clapis, 2001; Silva \& Santos, 2008, 2010). Nessa perspectiva, Kübler-Ross (1981) afirma que o tumor maligno e, em particular, o câncer de mama (Jesus \& Lopes, 2003), está quase sempre associado à idéia de morte iminente. Mesmo diante de bom prognóstico, ainda é forte a crença de que câncer e terminalidade são sinônimos (Rzeznik \& Dall'Agnol, 2000).

Segundo dados da literatura (Barnes et al., 2000; Biffi, 2003; Scorsolini-Comin, Santos \& Souza, 2009; Silva \& Santos, 2008, 2010; Sinding, 2003), estar com câncer é uma das experiências humanas mais impactantes, tanto do ponto de vista pessoal como familiar. A família de um paciente que se vê obrigado a enfrentar o câncer, com o diagnóstico sente-se abalada pelo inesperado e apenas com o decorrer do tempo consegue desenvolver esperança, solidariedade e fé para enfrentar a doença (Araújo \& Nascimento, 2004). 
Essa experiência de enfrentamento pode comprometer as relações familiares, ocasionando estresse, tensão e reativação de conflitos latentes, uma vez que, segundo Carvalho (2008), a doença altera o papel social do sujeito enfermo e a dinâmica familiar.

Stolagli, Evangelista e Camargo (2008) afirmam que certas doenças trazem impactos para o paciente e sua família em função do estigma que carregam, deixando-os fragilizados, à medida que abalam a estrutura emocional dos familiares $\mathrm{e}$ suas relações sociais. Nesse sentido, Baider (2003) afirma que a família não é um espelho sem reflexo e, por esse motivo, se mostra um sistema que reverbera o medo e as ansiedades da paciente e de cada um dos membros que compõem a unidade familiar. Para Souza e Espírito Santo (2008), a família é o principal agente responsável pela promoção de conforto e segurança ao paciente, sendo que para os familiares pode ser tão difícil enfrentar o câncer quanto o é para seu ente acometido.

O câncer, ainda que clinicamente não se apresente de súbito, pois geralmente se desenvolve insidiosamente, é quase sempre vivenciado pela família, em um primeiro momento, como uma doença que ameaça a vida (Lopes, 2000). De todo modo, como afirmam Maluf, Mori e Barros (2005) e Parkes (1998), o diagnóstico será vivenciado de acordo com os significados que a pessoa enferma e seus familiares atribuírem-no a partir de suas experiências anteriores de perdas. A vivência da doença também é permeada por medos, angústias e fantasias, que influenciarão o modo particular como a família irá encarar o tratamento e suas vicissitudes. Em grande medida, a doença será enfrentada pelo paciente conforme as vivências da família (Waidman \& Elsen, 2004).

De acordo com estudos realizados por Fitch e Allard (2007) e Harrow, Wells, Barbour e Cable (2008), o diagnóstico do câncer de mama tem o potencial de causar impactos também nos companheiros das mulheres que são acometidas pela doença, sendo vivenciado como um acontecimento inesperado, que afeta diversas esferas de suas vidas. Isso se deve ao fato de que o diagnóstico de câncer de mama, assim como de qualquer outra neoplasia, comumente coloca a pessoa acometida e seus familiares diante da perspectiva da morte (Conceição \& Lopes, 2008) e da luta pela sobrevivência (Anjos \& Zago, 2006; Gimenes \& Queiroz, 1997).

Em concordância com esses apontamentos, Maia (2005) afirma que o diagnóstico de câncer é percebido como uma ameaça de morte e, a partir desse momento, a consciência da mortalidade se torna intensificada, tanto para os pacientes como para os familiares. Fica claro que o diagnóstico do câncer traz, tanto para o paciente acometido, quanto para os familiares, uma incômoda aproximação em relação à condição humana de sermos todos seres-para-a-morte (Heidegger, 2002/1927). Nesse cenário, quando a questão da possibilidade de morte e da luta pela sobrevivência se impõe, a visão de curto prazo prevalece. Projetos e metas futuras parecem muito distantes ou inatingíveis e o horizonte existencial pode se estreitar nesse momento crítico da existência.

Segundo Raveis e Pretter (2005), filhas de mulheres acometidas pelo câncer de mama também passam a enfrentar um momento de profunda crise a partir do diagnóstico de suas mães, permeado por exposição a inúmeros desafios e preocupações relativas à vida e à morte. Porém, ao se verem diante de uma etapa existencialmente dramática, precisam encarar a enfermidade e o início do tratamento de suas mães. Isso caracteriza essas filhas como uma população vulnerável, que também inspira cuidados. Em maridos cujas mulheres enfrentam o câncer de mama, os sentidos construídos para a doença da parceira tornam evidentes os estigmas encontrados ao longo da história do câncer e acabam, assim, mobilizando diversos sentimentos em virtude da expectativa de um desfecho fatal (Ferreira, Almeida \& Rasera, 2008; Schmid-Büchi, Halfens, Dassen \& Van Den Borne, 2008). Estudo mostra que a família que enfrenta o câncer costuma apresentar uma crença profunda de que a doença é necessariamente fatal e o choque sofrido no momento do diagnóstico pode ser ainda maior se paciente e familiares estiverem se confrontando com a idéia de mortalidade pela primeira vez (Mesquita, Magalhães, Almeida, Carvalho \& Mota Rego, 2007).

Diante dessas evidências encontradas na literatura, fica patente a necessidade de investigar a experiência de familiares de mulheres que enfrentam o câncer de mama. Nessa vertente, o presente estudo teve por objetivo compreender a vivência de familiares de mulheres acometidas pelo câncer de mama em relação à possibilidade de morte.

A partir deste estudo, espera-se que essas vivências possam ser melhor conhecidas e compreendidas, permitindo identificar as vulnerabilidades dessas famílias e suas necessidades de cuidado. Desse modo, será possível elaborar modalidades de intervenção que possam beneficiar essa clientela e contribuir para a humanização do cuidado, ao incluir a família como unidade de tratamento no contexto do câncer de mama.

\section{Método}

Trata-se de um estudo descritivo e exploratório, conduzido sob um enfoque de pesquisa qualitativa apoiada no referencial teórico da Psicologia Fenomenológica (Forghieri, 2004). Ao investigar o fenômeno da possibilidade de morte a partir da perspectiva de quem o vivencia, ou seja, de seus protagonistas, a pesquisadora seguiu na direção de desvelar o universo de significados, motivos, aspirações, crenças, valores e atitudes (Minayo, 2006, 2008) que os familiares de mulheres mastectomizadas atribuem à possibilidade de morte, após ter sido diagnosticado o câncer de mama. Para a Fenomenologia, ao trabalhar com determinado fenômeno, considera-se que o objeto em estudo não existe em si, mas sempre em relação com o sujeito que o vivencia (Martins, 2006).

\section{Participantes}

Participaram do estudo 13 familiares adultos de mulheres submetidas à mastectomia (total ou parcial) dentro de um período pré-estabelecido de, no mínimo, um ano e, no máximo, cinco anos, atendidas em um serviço público universitário de reabilitação psicossocial de um município do nordeste do Estado de São Paulo. Em relação ao grau de parentesco, sete entrevistados eram filhos (cinco mulheres e dois homens), quatro maridos, uma nora e um participante 
estava na condição simultânea de marido e genro, visto que tanto sua sogra quanto sua esposa já haviam passado pela experiência do câncer de mama.

Os participantes tinham idades variando de 19 a 79 anos, nível de instrução de ensino médio incompleto a superior completo e profissões diversificadas, predominando atividades laborais que exigiam baixo nível de qualificação profissional, como cabeleireiro, auxiliar de escritório e comerciante. A maioria dos filhos era solteira e residia com a mãe. O tempo de cirurgia das pacientes cujos familiares foram entrevistados variou de um ano e cinco meses a quatro anos e sete meses.

A definição do critério baseado no tempo de tratamento das mulheres mastectomizadas obedeceu à necessidade de garantir que o processo de captação dos participantes incluísse indivíduos que já haviam vivenciado o período geralmente considerado mais crítico da terapêutica, que abrange o primeiro ano. O limite máximo de cinco anos foi escolhido para assegurar que o distanciamento temporal em relação às vicissitudes do tratamento não fosse demasiadamente longo, de modo a dificultar a recordação tanto das experiências positivas, como das lembranças traumáticas suscitadas pelo evento.

\section{Instrumento e Procedimentos}

Como instrumento de coleta foi utilizada a entrevista fenomenológica. Trata-se de uma entrevista aberta, que na presente investigação foi norteada pela questão: "Como foi, para você, ter um familiar com câncer de mama?".

Foram consultados os registros das mulheres que estavam frequentando o serviço e selecionadas aquelas que preenchiam o critério de tempo de tratamento. Com base no referencial de pesquisa fenomenológica adotado, não foram pré-estabelecidos critérios de quais pessoas seriam consideradas familiares. A proposta da investigação foi formulada pessoalmente pela pesquisadora às pacientes do serviço de reabilitação, solicitando que elas convidassem seus familiares para participarem do estudo, especificando-se apenas que eles deveriam ter acima de 18 anos e ter disponibilidade para participar do estudo. Portanto, foi a partir da vivência singular de cada mulher mastectomizada que foi construído o conceito de família privilegiado no presente estudo.

No contato com as pacientes foram apresentados os objetivos da pesquisa, enfatizando-se que a participação de seus familiares era inteiramente voluntária e que uma eventual recusa não acarretaria prejuízos à continuidade do seu atendimento. Nesse contexto, elas sugeriram o familiar que, no seu entendimento, seria um potencial informante-chave na questão contemplada pelo estudo. Em seguida, assinavam um Termo de Consentimento Livre e Esclarecido (TCLE), no qual autorizavam que a pesquisadora entrasse em contato com o familiar indicado.

$\mathrm{Na}$ abordagem dos familiares, por telefone, a pesquisadora explicava as características e objetivos do estudo e solicitava sua colaboração. Havendo anuência para participar como voluntários da pesquisa, era agendada uma data e negociado o local mais conveniente para a realização da entrevista.
As entrevistas foram realizadas individualmente e em situação face a face, na residência dos familiares (cinco colaboradores) ou em uma sala reservada do serviço (oito colaboradores). Nesse encontro a pesquisadora apresentou um segundo TCLE, dirigido ao familiar, que o leu e assinou, formalizando assim sua concordância com os termos propostos na pesquisa.

As entrevistas foram audiogravadas, mediante consentimento dos participantes, e duraram cerca de uma hora. O período de coleta de dados se estendeu de agosto de 2006 a junho de 2007. O estudo foi aprovado pelo Comitê de Ética em Pesquisa da instituição a qual se vincula o serviço de reabilitação.

\section{Análise dos dados}

Guiando-se pelo referencial fenomenológico, as entrevistas foram transcritas na íntegra e literalmente, constituindo o corpus de análise. Nas sucessivas leituras empreendidas, focalizou-se o fenômeno pesquisado em busca das unidades de significado que, uma vez agrupadas, deram origem aos eixos temáticos, levando-se em consideração as diretrizes de análise sugeridas por estudos conduzidos sob o enfoque fenomenológico (Boemer, 1994; Forghieri,2004; Valle, 1997).

\section{Resultados e Discussão}

A análise fenomenológica permitiu desvelar três eixos temáticos: "Os familiares reconhecem a presença do estigma do câncer", "Os familiares percebem a morte como possibilidade concreta" e "Os familiares sentem necessidade de ser-com-um-profissional-especializado". Para ilustrar tais eixos serão utilizadas algumas falas, acompanhadas de nomes fictícios, de modo a preservar a identidade dos participantes. As categorias temáticas serão apresentadas e discutidas, simultaneamente.

\section{Os familiares reconhecem a presença do estigma do câncer}

Em suas falas, os familiares delineiam o significado do câncer de mama como uma doença monstruosa, abominável, deformadora e mutilante. Um mal irreversível, incurável e, consequentemente, fatal. Essa imagem aniquiladora contribui para deflagrar o choque sofrido no momento de definição do diagnóstico: "É um monstro até. O nome câncer, ele é muito forte." (Antônia, 27 anos, filha).

O diagnóstico do câncer de mama é, em um primeiro momento, identificado pelos familiares como uma sentença de morte (Baider, 2003; Maia, 2005; Maluf, Mori \& Barros, 2005; Parkes, 1998; Souza \& Espírito Santo, 2008; Stolagli, Evangelista \& Camargo, 2008). Essa significação parece ser potencializada pela alta incidência deste tipo de câncer na população feminina brasileira (Instituto Nacional de Câncer, 2009), mas também pelo estigma que essa enfermidade carrega (Carvalho, 2008). 
"A imagem era sempre pensar em morte..." (Carmelinda, 55 anos, filha). “A princípio, é: pronto, acabou... todo mundo já tem uma imagem já de: vou morrer... A primeira imagem era assim... muita gente associa câncer assim: nossa! morte!" (Flávia, 19 anos, filha)

Porém, alguns familiares participantes deste estudo conseguiram reconhecer o quanto essa relação, a princípio indissociável, estabelecida entre diagnóstico de câncer de mama e morte, foi construída culturalmente ao longo da história, caracterizando o estigma social do câncer. Para Anjos e Zago (2006), conhecer essa história de significados construída pela família e as influências socioculturais que interferem nessa atribuição de significado é de extrema importância para que tais fatores sejam levados em consideração na trajetória da terapêutica e na definição do plano de cuidados. Segundo as referidas autoras, é preciso compreender como a doença e o tratamento afetam o paciente e como ele as interpreta.

...talvez por terem pintado a coisa de uma maneira muito drástica... Do ouvido no passado eu transferi essa dramaticidade pro caso meu... (Sebastião, 63 anos, genro/marido).

Porque antigamente era uma coisa, assim, condenatório, se era câncer: pum... era morte. (Maria, 42 anos, nora).

A esse respeito, Araújo e Nascimento (2004) referem que o diagnóstico de uma condição mórbida como o câncer de mama produz na família, principalmente no primeiro momento, muita dor e sofrimento, uma vez que essa patologia está impregnada de significações negativas. A crença de que a doença não tem cura, que segue um curso progressivo e irreversível, tornando-se um mal irremediável, insidioso e altamente destruidor que se instala no silêncio dos órgãos e, sorrateiramente, vai se espalhando pelo corpo, entre outras representações afins, faz da doença maligna um prenúncio de decadência física, psicológica e moral:

Só que esse problema de câncer é uma doença muito ingrata, então a gente pensa que não vai acontecer nada, que vai ficar no estágio que tá e, quando a gente vai querer acordar pra fazer a cirurgia, às vezes não dá nem tempo, porque aí ele pode se alastrar, então é melhor cortar no início, que a cura sempre é maior, né. (Sérgio, 52 anos, marido).

Como pôde ser amplamente percebido no corpus analisado no presente estudo, os relatos das famílias coincidem com a imagem do câncer encontrada em grande parte dos depoimentos que povoam a literatura sobre o tema e que têm seu exemplo mais ilustrativo na metáfora do bicho que devora o corpo do paciente (Baider, 2003). Os participantes do estudo conduzido por essa autora referiram-se ao câncer como uma sentença de morte, uma doença mortal e de rápida evolução, uma doença traiçoeira, uma espécie de inimigo latente que se desenvolve com extrema rapidez após ser descoberto, levando ao aniquilamento do organismo que o hospeda.

Na presente investigação foram constatadas percepções semelhantes às encontradas na literatura. A vivência do câncer, por parte dos familiares, como um mal avassalador, corrosivo e voraz, suscita profunda desconfiança quanto à possibilidade de reversão do quadro, uma vez que tenha sido deflagrado o processo silencioso da doença. A mera constatação médica do câncer, consumada no ato do diagnóstico, é significada como prenúncio inevitável de um fim iminente, que antecipa o descontrole que leva a incidências metastáticas.

Sabe, eu acho assim (...) câncer pra mim é igualzinho dívida: você pede emprestado pra um pra cobrir aquele, então o que acontece? Você tira daqui, ele ramifica do outro lado, porque se ele já se manifestou de algum lugar ele veio, e o nosso corpo é tudo células... (...) O corpo é formado por células, se ele chegou lá em cima, ele veio de algum lugar, ele não vem de fora pra dentro... (Betânia, 54 anos, filha).

Nesse excerto de fala apresentado, a etiologia endógena do câncer é reconhecida, porém a origem do câncer é cercada de mistério. A percepção de que o câncer vem "de dentro" abala o modelo etiológico mais difundido culturalmente para as doenças de um modo geral, que corresponde a um processo que se instala de "fora para dentro", à semelhança do que ocorre com as patologias desencadeadas pela contaminação por agentes infecciosos, como vírus e bactérias. Um dos aspectos mais intrigantes do câncer, ressaltado pela fala de Betânia, é que o processo, além de insidioso, nasce nas profundezas silenciosas do próprio organismo ("de algum lugar ele veio"), em alguma região obscura na qual começam a proliferar, de forma desordenada, células malignas. Não é um ser estranho, alienígena que invade e contamina a pureza do corpo, mas a própria matéria-prima que o constitui, pois o mal nasce das células que passam a fustigar o próprio organismo e ameaçam aniquilar a vida, solapando as esperanças de cura. Essa percepção é dominante, apesar da evidência de que nem todos os tipos de câncer têm evolução altamente agressiva.

\section{Os familiares percebem a morte como possibilidade concreta}

A análise dos depoimentos que compõem esse núcleo temático desvela a percepção da possibilidade de morte iminente da mulher acometida pelo câncer de mama. Esse risco, sentido como uma ameaça palpável, foi referido nos depoimentos de todos os participantes, a despeito de a palavra "morte" nem sempre ter sido utilizada com todas as letras, embora aparecesse claramente insinuada ou sugerida nas entrelinhas:

No início é aquela, aquele medo da perda... Na minha cidade a gente fala que a gente já espera o pior em iminência, né, rapidamente... Cê coloca, como diz o ditado, o carro na frente dos bois, então cê já pensa no pior logo de cara quando fala de câncer... (Sebastião, 63 anos, genro/marido).

Pelo tabu, assim, de não conhecer, ficou, fica naquela: "o quê que será que vai acontecer agora?" O câncer, todo mundo fala: câncer! Falam: NOSSA, um CÂNCER... Todo mundo fica meio com medo do pior... (Paulo, 21 anos, filho).

Percebeu-se neste estudo, assim como no realizado por Trincaus e Corrêa (2007), que, na maioria das vezes, os fa- 
miliares não estão em condições de falar diretamente sobre a possibilidade de morte. Para as autoras, apesar de ser dada a todo ser humano a certeza de morte, muitos só adquirem consciência de sua finitude quando se deparam com uma situação crítica, que reflita a necessidade do ser-aí buscar o sentido existencial deste chegar-ao-fim, o que se configura como bastante assustador para os familiares.

De forma explícita ou velada, a sombra onipresente da morte, símbolo por excelência do desconhecido, paira sobre os familiares. Como referem Baider (2003) e Lopes (2000), o diagnóstico do câncer é visto pelo paciente e sua família como um espectro que ameaça a continuidade da existência, desfazendo os laços afetivos, interrompendo projetos e privando a pessoa acometida do convívio familiar. A morte passa a existir para a família como possibilidade concreta, que atravessa a existência dos seus membros e que pode ocorrer a qualquer momento, fazendo sua aparição quando menos se espera, uma vez que se está diante do imponderável, daquilo sobre o qual não se tem controle. Um dos medos humanos mais cruciais talvez seja o de ser pego de surpresa, ser colhido pela adversidade em algum ponto de sua biografia, quando se está "desprevenido" e se percebe lançado rumo ao desconhecido sobre o qual não se tem controle. Na verdade, essa facticidade acompanha o existir humano ao longo de toda sua trajetória, contudo parece ficar exacerbada diante da experiência de uma enfermidade potencialmente fatal como o câncer (Scorsolini-Comin, Souza \& Santos, 2008).

Mais especificamente, a ameaça temida é a possibilidade de perder o controle sobre si e o próprio corpo, que vê sua integridade e individualidade invadidas por forças avassaladoras; é a perspectiva de ficar com a vida por um fio, à mercê dos caprichos de uma doença insidiosa e proliferativa, que acentua a experiência paradoxal de estar vivo, dada a dualidade vida-morte que pontua o caminhar humano. Além disso, a possibilidade da mulher sofrer uma recidiva e da doença se espalhar, compromentendo outros órgãos e funções, também pode levar a família a ter medo da morte (Stolagli, Evangelista \& Camargo, 2008).

Tinha sempre aquela preocupação, será que ela vai ficar curada? E o medo sempre é o maior, o medo sempre que é o óbito, né. A gente sempre sabe que é consequência, né, ou cura ou vai a óbito, né. (Sérgio, 52 anos, marido).

Nota-se, nesse excerto de fala, que o câncer, na percepção do companheiro de uma paciente, não admite meio termo: ou é exterminado ou mata o hospedeiro. Nessa situação liminar, a experiência dos limites do viver e do morrer torna-se bastante palpável, assim como a tênue separação que existe entre a concretização da condição de finitude, operada pela doença, e a esperança de vida depositada no tratamento (Fonseca, 1999). O tratamento, por sua vez, é experimentado de forma paradoxal: pode levar à cura ou a remissão, mas também é doloroso e inflige sofrimento (Scorsolini-Comin, Santos \& Souza, 2009). A dinâmica familiar é alterada, uma vez que a angústia de existir enquanto ser-para-a-morte (Heidegger, 2002/1927), começa a fazer parte do cotidiano de todos os membros da família. Essa percepção irá permear inclusive o rol de estratégias de cuidado que os familiares e amigos irão utilizar com a parente enferma (Sinding, 2003).
Ao comparar a situação que os familiares vivenciaram com outras experiências de perdas de pessoas significativas, nas quais a morte havia sido inevitável, em decorrência do câncer ou de qualquer outra causa, os participantes deixaram claro o quanto passaram a visualizar a possibilidade de finitude como bastante concreta, amplificada por vivências anteriores de perdas acumuladas em seu viver:

...mesmo porque eu perdi uma sobrinha com 33 anos faz uns três anos, então isso que ela morreu... acho que por ser mais jovem, né... ela nunca teve nada e a hora em que ela descobriu, tava com câncer todo e ela durou menos de um ano... (...) o pai da minha mãe também morreu de câncer, eu não me lembro onde... (...) logo depois que morreu minha sobrinha, morreu também uma grande amiga minha. (Carmelinda, 55 anos, filha).

A esse respeito, Baider (2003) destaca que a variabilidade do impacto psicossocial da enfermidade está ligada diretamente às características psicológicas que são anteriores à enfermidade. No presente estudo, tal como exemplificado no trabalho de Maia (2005), constatamos que as repercussões psicológicas são influenciadas também pelas experiências anteriores de perdas traumáticas que afetaram o viver dos familiares:

Inclusive na nossa família teve uma tia que já faleceu desse problema. Nova, inclusive. A gente sabe que uma doença desse tipo, se não tratada a tempo... (João, 43 anos, filho).

...e eu vinha vindo de uma perda recente também, né. Minha mãe faleceu aqui dentro de casa... (...) Eu vi primo meu morrer na cama com câncer de garganta. (Sebastião, 63 anos, genro/ marido).

Essas falas sugerem que a vivência do diagnóstico de câncer de mama reatualiza perdas pregressas e coloca os familiares da mulher acometida em contato profundo tanto com seus conteúdos internos, como com sua realidade de ser vulnerável e finito, podendo evidenciar a não-elaboração de experiências traumáticas pregressas. Quando essas questões não são elaboradas, configura-se a situação do luto complicado (Maluf et al., 2005; Parkes, 1998).

Sendo a própria morte uma experiência irrepresentável, o contato que cada ser vivente pode manter com ela é apenas indireto, por intermédio da morte do outro. Por essa razão a experiência de manter um familiar com câncer evoca tão fortemente reminiscências de situações semelhantes vividas no contato com outras pessoas, inclusive parentes, que vivenciaram e/ou sucumbiram à doença, geralmente após um período de sofrimento e dor.

Esses modos de dizer, que desvelam a presença da morte, permearam de formas distintas as entrevistas, bem como marcaram momentos diversos de uma mesma entrevista. É possível visualizar, nos excertos de falas reproduzidos anteriormente, algumas situações expressas nas entrevistas que deixam clara ou de forma apenas insinuada a percepção de que morte está sempre à espreita, rondando os vivos, gerando inquietude e desassossego. A perspectiva da finitude permeia suas narrativas, porém, de forma implícita. A necessidade de velar ou, no máximo, 
de se permitir dizer apenas implicitamente sobre o morrer, revela a carga simbólica que a própria palavra morte carrega na cultura ocidental. Normalmente, esse termo aparece minimizado e rarefeito nos subterfúgios e nas entrelinhas dos discursos dos familiares, no não-dito que se oculta nas dobras da linguagem.

Em relação à posição assumida pelos maridos frente à doença, a aproximação aos sentidos desvelados nos depoimentos dos cônjuges em relação ao câncer de mama das parceiras mostra que os maridos se apropriam dos conceitos que a história e o contexto sociocultural do câncer cristalizaram para a doença. Esses significados mobilizam, nos indivíduos, surpresa e dor psíquica, em virtude de anteciparem um ineludível desfecho de morte (Ferreira et al., 2008).

É uma pessoa que você escolheu pra viver a vida inteira do teu lado, então o máximo que você puder viver perto dela, você quer... (Eu pensava) eu vou acabar é ficando sozinho mesmo porque é algo... o sentimento de perda, ele abala a gente duma tal maneira que não tem... não tem o que tampar esse vazio. (Sebastião, 63 anos, genro/marido).

A fala de Sebastião traduz, de maneira pungente, o sofrimento emocional que aflige o companheiro da mulher acometida pelo câncer de mama, assim como demonstram os estudos de Fitch e Allard (2007) e Harrow et al. (2008). Isso aponta para a necessidade de oferecer uma assistência interdisciplinar às famílias e, em especial, aos casais, que objetive construir, com eles, outros sentidos para o câncer (Ferreira et al., 2008), priorizando-se a flexibilidade de estratégias de enfrentamento durante todas as fases do tratamento (Gimenes \& Queiroz, 1997) e, até mesmo, possibilidades de abertura de novos horizontes existenciais (Kübler-Ross, 1981; Silva \& Santos, 2008; Stolagli, 2008; Trincaus \& Côrrea, 2007; Westman et al., 2006). Nesse contexto, é fundamental que os familiares se percebam como peça importante do tratamento, para que se sintam participantes ativos do processo de superação da doença e para que possam extrair da experiência com o câncer um significado positivo para suas próprias vidas. Estudo de Rzeznik e Dall'Agnol (2000) confirma que é possível que esse contexto de vida seja transformador para os membros da família.

\section{Os familiares sentem necessidade de ser-com-um- profissional-especializado}

Os entrevistados valorizaram, em suas falas, a importância dos profissionais de saúde que os acolheram e orientaram durante o enfrentamento do câncer de mama, mesmo quando mantiveram encontros breves ou intermediados pela paciente.

Eles conversavam, às vezes até muito rápido, porque era o tempo pra arrumar ela pra examinar... É muito rápido, mas o pouco que a gente conversava, ele sempre nos encorajava, né. (Sérgio, 52 anos, marido)

Porém, em alguns casos, esse contato breve não foi considerado satisfatório, pois não supriu plenamente as necessidades dos familiares, que sentiram a ausência de acolhimento por parte de profissionais especializados, com quem esperavam poder compartilhar suas dúvidas, angústias, dificuldades, desafios e vivências despertadas pelo enfrentamento do câncer de mama. Esses achados vão ao encontro do estudo realizado com familiares de mulheres mastectomizadas por Mesquita et al. (2007). Esses autores identificaram deficiências nas orientações oferecidas aos familiares, que muitas vezes são deixados de lado no tratamento.

Agora eu acho assim, me faltou nessa fase assim, uma palavra de incentivo, uma palavra de conforto, de orientação, de esclarecimento, talvez ainda me falte... Não houve, não teve de ninguém, cê vê, nós estamos em 2006, a medicina tá adiantada, agora não sei se é... Será que é do plano de saúde? Se for, que eu não acredito que seja falha do Dr. X, de dar uma orientação maior, ou então pedir pra que eu procurasse alguém, me indicasse alguém, eu não acredito... Se ele tivesse só preocupado com a minha esposa, já tava bom. (...) Agora, que você se sente num vazio muito grande, sente, mas é que não é um vazio apenas, é um vazio MUITO grande... mas é MUITO grande... (Sebastião, 63 anos, genro/marido)

O relato de um marido em específico revela o quanto receber orientações prévias acerca do que poderia ocorrer durante o tratamento amenizou seu impacto psicológico. Esse participante ficou sensibilizado com o apoio recebido de um colega que já havia passado pela experiência do câncer com sua esposa:

...o momento, ele é tenso, né, porque no momento que ela tá em tratamento, você não sabe como ela vai reagir, e teve o meu colega lá, que teve a esposa dele, e ele passou pra mim... como se diz, eu tava bem orientado... (Clemente, 51 anos, marido)

Compartilhar com outros a experiência de combate à doença parece ter exercido um efeito poderoso sobre Clemente, que pôde sentir-se apoiado e encontrar novos significados para a própria situação vivida, uma vez que a doença coloca em marcha um conhecimento que precisa ser continuamente reestruturado em cada processo interativo específico (Tavares \& Trad, 2005).

Nesse sentido, os familiares deixam claro que os esclarecimentos prestados pelos médicos que acompanhavam a paciente, ou por conhecidos que já haviam passado pela mesma experiência, foram valiosos e os auxiliaram a se orientar na travessia do tratamento, na medida em que indicaram um caminho a seguir e como proceder para superar ou abrandar as adversidades inerentes ao ser-no-mundo na condição de familiar de uma mulher com câncer de mama. Em um estudo semelhante (Westman et al., 2006), os autores identificaram que, neste âmbito, configura-se claramente a necessidade de apoio existencial, que pode ser parcialmente suprida pelos profissionais de saúde, assim como por outros familiares e amigos.

Em linhas gerais, os resultados corroboram a literatura da área (Fonseca, 1999; Peres \& Santos, 2009; Tavares \& Trad, 2005; Trincaus \& Côrrea, 2007).

Os achados se aproximam dos resultados obtidos por Waidman e Elsen (2004), que evidenciam que a família que 
convive com uma pessoa com câncer precisa ser compreendida, apoiada e ajudada não só pela rede social primária que a cerca, como também pelo profissional que a assiste: “...mas depois conversa o médico, foi muito, né, conversa muito, né, então ele nos orientou, explicou direitinho o que era, né... o quê que tinha que ser feito, né.." (Sérgio, 52 anos, marido)

No que concerne às filhas, o estudo de Raveis e Pretter (2005) esclareceu que elas são confrontadas com a necessidade de integrar suas respostas emocionais às reações de suas mães, ao mesmo tempo em que se vêem diante da busca de meios que as auxiliem no processamento de suas preocupações sobre sua susceptibilidade pessoal. No presente estudo, as filhas que receberam apoio psicológico na época em que vivenciaram o câncer de mama de suas mães relataram o quanto a psicoterapia as auxiliou a superar suas dificuldades e a reconhecer a experiência pela qual estavam atravessando como um processo de aprimoramento pessoal:“É, vai fazer quatro anos que eu faço terapia e isso me ajudou bastante." (Carmelinda, 55 anos, filha)."Hoje eu vejo que, se não dava pra fazer uma terapia familiar, o certo era cada um estar fazendo a sua terapia. Porque é muita bagunça de sentimento. É... é um turbilhão de sentimentos negativos de culpa." (Antônia, 27 anos, filha).

Os achados reforçam a importância da comunicação entre pais e filhos no contexto do câncer de mama (Barnes et al., 2000). Movidos pelo desejo de conhecer mais sobre o câncer e seu tratamento, os próprios participantes sugeriram alternativas que poderiam ser valiosas no sentido de auxiliar os familiares que vivenciam experiências semelhantes. Vários inclusive se colocaram à disposição para auxiliar os serviços de apoio a implementarem projetos futuros junto a essa clientela:

Seria muito interessante se a pessoa fosse ao (serviço de reabilitação) que precisasse e que levasse alguém da família junto. (Lúcia, 30 anos, filha).

Os homens também podiam frequentar o (serviço de reabilitação); só que é um horário que os homens, a maioria, tá trabalhando, porque se os homens pudessem frequentar o (serviço de reabilitação), a cabeça deles mudava. (Clemente, 51 anos, marido).

Tem pessoas que não gostam nem de comentar. Eu já não ligo, minha mãe não liga.. A gente fala, orienta pessoas que tão passando por isso, que tão naquela dificuldade... (Antônia, 27 anos, filha).

A fala de Antônia sugere que a mãe, por frequentar um grupo de apoio e reabilitação psicossocial, tem uma relação mais franca e aberta com sua doença e, talvez por isso, seja capaz de orientar outras pessoas, que estão vivenciando uma situação semelhante a que lhe ocorrera. Desse modo, os grupos de apoio emergem nas falas dos participantes como um reduto de acolhimento e potencialização de recursos de enfrentamento, legitimados como uma alternativa importante de apoio familiar. Por serem constituídos por mulheres que enfrentam o câncer de mama, a identificação com as situações vividas é imediata. Na perspectiva de alguns participantes, a disponibilização desses grupos auxiliaria a preservar uma rede de segurança para os setores mais vulneráveis da sociedade.

O desejo explícito de receber informações qualificadas sobre a doença e o tratamento também é efeito do impacto que o conhecimento científico e biotecnológico tem sobre o funcionamento da sociedade contemporânea. Os familiares que participaram do presente estudo manifestaram seu desejo de conhecer mais sobre a doença e receber orientação sobre o tratamento, o que contrasta com certa percepção frequentemente difundida de que a família do paciente oncológico, para não sofrer, muitas vezes prefere não saber, evitando assim se envolver. É como se os participantes dissessem aos profissionais: "Podemos conversar?", valorizando contextos dialógicos e o compartilhamento de saberes como parte integrante do acolhimento. Esse discurso confirma a relevância da faceta educativa que está implícita no trabalho desenvolvido pelo setor saúde. Com efeito, os familiares parecem claramente reconhecer que deter conhecimento é uma forma de se apropriar dos acontecimentos significativos que lhes sucedem, fomentando seu empoderamento.

No contato com a pesquisadora, os familiares demonstraram a necessidade que sentiram, durante o longo percurso do tratamento, de estar-com-um-profissional-especializado, alguém com quem pudessem compartilhar suas dúvidas e angústias diante das situações vivenciadas nas diferentes etapas do processo de adoecer. Esse achado corrobora a necessidade de um cuidar que considere a subjetividade das vivências emocionais dos familiares e a singularidade de suas necessidades e expectativas como seres únicos que são (Jesus \& Lopes, 2003).

Nesse sentido, Almeida et al., (2001) destacam que as mulheres com câncer de mama e suas famílias necessitam de suporte constante dos profissionais de saúde, para que possam equilibrar as complexas conexões existentes entre a doença, seu tratamento e a possibilidade da recorrência do câncer. Esse apoio é imprescindível também para que eles possam vislumbrar novas possibilidades de organização do grupo familiar, após a doença ter causado uma perturbação no funcionamento da família (Biffi, 2003), em busca de uma melhor qualidade de vida (Souza \& Espírito Santo, 2008). Essa necessidade impõe um desafio atual ao sistema de saúde que, a despeito de agregar a orientação psicossocial e multiprofissional, em nossa realidade ainda está organizado de acordo com os preceitos da racionalidade técnico-científica que rege o modelo biomédico (Conceição \& Lopes, 2008).

\section{Considerações Finais}

Os resultados obtidos no presente estudo evidenciam que, não obstante a evolução científica e tecnológica que tem aperfeiçoado o diagnóstico e tratamento oncológico, resultando em melhor prognóstico para os pacientes, o fator humano ainda permanece como um ponto nevrálgico da assistência, uma vez que ainda não se incorporou ao sistema de saúde a necessidade de prover suporte integral aos familiares. Os participantes do presente estudo salientaram a falta de orientação, informação e acolhimento por parte dos profissionais, mas também se esforçaram para dar significados à experiência de distanciamento que perceberam nos médicos durante o trata- 
mento e reivindicaram maior atenção profissional, inclusive para a paciente. A inclusão dos familiares nos dispositivos de cuidado pode contribuir para minimizar o sofrimento que a situação inflige em todo o sistema familiar (Araújo \& Nascimento, 2004; Carvalho, 2008), tornando mais tolerável o convívio com a dor, a incerteza, a instabilidade e o imprevisível. Isso ajudaria os familiares a superarem os obstáculos enfrentados e a administrar melhor os sentimentos paradoxais que a experiência suscita (Biffi, 2003), de modo que possam crescer e amadurecer emocionalmente face à adversidade. Na medida em que se sintam mais acolhidos e fortalecidos, podem oferecer apoio mais efetivo para a paciente, reforçando os elos afetivos que os mantêm juntos.

Nessa direção, os conhecimentos sobre a vivência dos familiares de mulheres mastectomizadas, que foram desvelados pelo presente estudo, podem fornecer subsídios para o planejamento de estratégias de intervenção e/ou suporte psicológico a serem implementadas junto aos serviços de saúde, levando-se em consideração as reais necessidades não apenas das mulheres acometidas pelo câncer de mama, como também de sua rede de apoio familiar. É preciso estimular a inclusão da família nas distintas fases do tratamento, da etapa pré-diagnóstica até a reabilitação psicossocial e, quando for o caso, ao ingressarem nos cuidados paliativos. Com a progressiva elevação do tempo de sobrevida das pacientes, graças aos avanços terapêuticos que têm transformado o câncer em uma condição crônica de saúde, a integração da família à assistência tem sido uma necessidade crescente.

Como destaca Schmid-Büchi, Halfens, Dassen e Van Den Borne (2008), assegurar o atendimento psicológico à família é fundamental, na medida em que esta desempenha papel importante para a mulher acometida pelo câncer de mama, uma vez que as reações familiares contribuem de maneira decisiva para a recuperação da paciente. De acordo com os autores, mediante o acompanhamento disponibilizado aos familiares propiciam-se os meios para que também eles possam vivenciar seus dramas e conflitos emocionais relacionados à doença.

Ao se defrontarem diretamente com a doença grave, os familiares ficam angustiados, na medida em que se percebem diante da possibilidade de finitude do ser, perante a existência inexorável da morte como possibilidade concreta que atravessa a existência, podendo ocorrer a qualquer momento e com qualquer pessoa. $\mathrm{O}$ futuro se mostra, portanto, ameaçador e ao mesmo tempo incerto, e os familiares passam a perceber o outro e a si mesmos como seres-para-a-morte, o que os lança à angústia essencial constitutiva da condição humana.

Nas entrelinhas das falas dos entrevistados está presente a idéia de que, no cotidiano, os familiares também percebem pousar sobre seus ombros a sombra da morte e as dificuldades de lidar com a finitude humana. Essas dificuldades, que marcam os processos de subjetivação na contemporaneidade, são agravadas pela origem "misteriosa" do câncer, com sua representação coletiva de processo inescrutável e silencioso que se abriga no interior do corpo, minando gradualmente a vitalidade da pessoa acometida.

A todo ser humano foi dada a certeza da morte, porém buscamos a todo custo escapar a essa idéia, como defesa para mantermos o sentimento de invulnerabilidade. Por isso, diante do diagnóstico de uma doença complexa como o câncer de mama, carregada de sentidos permeados pela relação historicamente construída com a morte, os familiares vivenciam com sofrimento essa possibilidade. A partir da associação com o sofrimento e a rememoração da perda de outros entes queridos, experimentadas anteriormente ao diagnóstico da paciente com câncer de mama, os familiares são forçados a se aproximarem da compreensão da condição humana de serem, eles próprios, também seres-para-a-morte. Nota-se que, com a tomada de consciência dessa marca da finitude, os familiares, enquanto seres-aí, sentem a necessidade de buscar um sentido existencial desse chegar-ao-fim (Trincaus \& Corrêa, 2007).

Ao sentirem a necessidade de serem-com-um-profissional-especializado, pode-se dizer que os familiares desvelam a necessidade de dividir suas angústias, suscitadas pelo medo da morte da parente com câncer de mama. Quando se sentem acolhidos nesse movimento de busca de apoio que dê significado para seu existir, sentem-se reconfortados e fortalecidos para continuarem a compartilhar o caminho do enfrentamento da condição essencial da vida, que é a realidade inexorável da finitude, mas também com a possibilidade de usufruírem do estar-com. Como relatam, principalmente os companheiros das mulheres mastectomizadas, lutar contra forças da natureza tão poderosas como um tumor maligno é uma condição liminar que ameaça aniquilar as conquistas construídas e sedimentadas durante os anos de convívio conjugal, além de exterminar a possibilidade de sustentar planos e sonhos a longo prazo, o que desperta profundos sentimentos de desamparo e solidão.

Em função disso, a condição de estar-com-os-familiares é uma habilidade essencial a ser desenvolvida por profissionais de saúde, principalmente no momento em que a família toma conhecimento do diagnóstico. Esse é um dos momentos críticos em que o grupo familiar mais necessita de acolhimento e escuta, para que consiga significar esse processo de maneira positiva.

De acordo com Silva e Santos (2008), no momento de enfrentar um câncer, a família se depara com o conflito entre precisar apoiar o ente querido e aceitar a presença da neoplasia no seio familiar. Nesse contexto, o profissional de saúde deve considerar o sentido conferido ao diagnóstico do câncer de mama como anúncio que antecipa a possibilidade de morte para os familiares, a fim de se aproximar dos sentimentos suscitados no momento da notificação do diagnóstico e, assim, exercer um cuidado autêntico que contemple o sofrimento das famílias.

Assim, com os resultados obtidos nesta investigação fenomenológica, pretende-se, como ressalta Carvalho (2008), despertar a atenção dos profissionais que atuam em oncologia para a importância extrema de voltarem sua atenção também ao grupo familiar, que se vê diante da inevitabilidade de pensar questões relacionadas à morte a partir do diagnóstico do câncer de mama. É preciso suprir a família com informações dosadas segundo suas necessidades e apoiá-la emocionalmente, para ajudá-la a reduzir as tensões e evitar o colapso das forças que estão em jogo durante o tratamento.

Para aprimorar a qualidade da assistência prestada à família é necessário considerar a unidade paciente-família como um ente a ser cuidado e compreendê-la como ser-para-a-morte (Heidegger, 2002/1927), que vivencia a angústia 
perante sua possibilidade concreta de cessar sua existência. $\mathrm{O}$ profissional precisa ser sensível à fronteira porosa que separa o sofrimento da mulher acometida e a dor emocional dos familiares, de maneira a poder atender a necessidade singular dessa estrutura formada pelo ser-com-um-profissional-especializado e se constituir como tal. Afinal, a despeito dos avanços do conhecimento médico nas últimas décadas e dos resultados cada vez mais animadores do tratamento, o câncer de mama permanece como um dos grandes desafios da saúde da mulher.

\section{Referências}

Almeida, A. M., Mamede, M. V., Panobianco, M. S., Prado, M. A. S., \& Clapis, M. J. (2001). Construindo o significado de recorrência da doença: a experiência de mulheres com câncer de mama. Revista Latino-Americana de Enfermagem, 9(5), 63-69.

Anjos, A. C. Y., \& Zago, M. F. (2006). A experiência da terapêutica quimioterápica oncológica na visão do paciente. Revista Latino-Americana de Enfermagem, 14(1), 33-40.

Araújo, J. S., \& Nascimento, M. A. A. (2004). Atuação da família frente ao processo saúde-doença de um familiar com câncer de mama. Revista Brasileira de Enfermagem, 57(3), 274-278.

Baider, L. (2003). Câncer y família: aspectos teóricos e terapêuticos. Revista Internacional de Psicologia Clinica y de la Salud, 3(1), 505-520.

Barnes, J., Kroll, L., Burke, O., Lee, J., Jones, A. \& Stein, A. (2000). Qualitative interview study of communication between parents and children about maternal breast cancer. The Western Journal of Medicine, 173(6), 385-389.

Biffi, R. G. (2003). A dinâmica familiar de um grupo de mulheres com câncer de mama. Tese de Doutorado, Universidade de São Paulo, Ribeirão Preto, SP.

Boemer, M. R. (1994). A condução de estudos segundo a metodologia de investigação fenomenológica. Revista LatinoAmericana de Enfermagem, 2(1), 83-94.

Carvalho, C. S. U. (2008). A necessária atenção à família do paciente oncológico. Revista Brasileira de Cancerologia; 54(1), 87-96.

Conceição, L. L., \& Lopes, R. L. M. (2008). O cotidiano de mulheres mastectomizadas: do diagnóstico à quimioterapia. Revista Enfermagem UERJ, 16(1), 26-31.

Fitch, M. I., \& Allard, M. (2007). Perspectives of husbands of women with breast cancer: impact and response. Canadian Oncology Nursing Journal, 17(2), 66-78.

Ferreira, C. B., Almeida, A. M., \& Rasera, E. F. (2008). Sentidos do diagnóstico por câncer de mama feminino para casais que o vivenciaram. Interface: Comunicação, Saúde e Educação, 12(27), 863-871.

Fonseca, S. M. (1999). A dialética da representação do tratamento quimioterápico para o doente oncológico: Vida versus morte. Dissertação de Mestrado, Universidade de São Paulo, São Paulo.

Forghieri, Y. C. (2004). Psicologia fenomenológica: Fundamentos, método e pesquisa (2 ${ }^{\mathrm{a}} \mathrm{ed}$.). São Paulo: Pioneira.

Gimenes, M. G. G. \& Queiroz, E. (1997). As diferentes fases de enfrentamento durante o primeiro ano após a mastectomia. Em M. G. G. Gimenes (Org.), A mulher e o câncer (pp. 173-196). Campinas: Livro Pleno.
Harrow, A., Wells, M., Barbour, R., \& Cable, S. (2008). Ambiguity and uncertainty: the ongoing concerns of male partners of women treated for breast cancer. European Journal of Oncology Nursing, 12(4), 349-356.

Heidegger, M. (2002). Ser e tempo: Parte 1. (M. S. C. Shuback, Trad.). Petrópolis: Vozes. (Trabalho original publicado em 1927).

Instituto Nacional de Câncer (2009). Estimativas 2010: incidência de câncer no Brasil. Rio de Janeiro: Ministério da Saúde. Retirado em 11/06/2011, de http://www.inca.gov.br/estimativa/2010/ index.asp?link=conteudo_view.asp\&ID=5.

Jesus, L. L. C., \& Lopes, R. L. M. (2003). Considerando o câncer de mama e a quimioterapia na vida da mulher. Revista Enfermagem UERJ, 1(2), 208-211.

Kübler-Ross, E. (1981). Sobre a morte e o morrer. (P. Menezes, Trad.). São Paulo: Martins Fontes. (Trabalho original publicado em 1969).

Lopes, D. P. L. O. (2000). A organização familiar e o acontecer do tratamento da criança com câncer. Dissertação de Mestrado, , Universidade de São Paulo, Ribeirão Preto, SP.

Maia, S. A. F. (2005). Câncer e morte: o impacto sobre o paciente e a família. Trabalho de Conclusão do Curso de Especialização em Psiconcologia, Hospital Ernesto Gaertner, Curitiba, PR.

Maluf, M. F. M., Mori, L., \& Barros, A. C. S. D. (2005). O impacto psicológico do câncer de mama. Revista Brasileira de Cancerologia, 51(2), 149-154.

Martins, J. (2006). A ontologia de Heidegger. In J. Martins \& M. A. V. Bicudo (Eds.), Estudos sobre existencialismo, fenomenologia e educação (2a ed) (pp. 43-56). São Paulo: Centauro.

Mesquita, M. E., Magalhães S., R., Almeida, A. M., Carvalho, F. A. F., \& Mota Rego, C. D. (2007). Comportamentos da família diante do diagnóstico de câncer de mama. Enfermería Global, 10, 1-10.

Minayo, M. C. S. (2006). O desafio do conhecimento: Pesquisa qualitativa em saúde. São Paulo-Rio de Janeiro: HucitecAbrasco.

Minayo, M. C. S. (2008). O desafio da pesquisa social. In M. C. S. Minayo, R. Gomes, \& Deslandes (Eds.), Pesquisa social: Teoria, método e criatividade (27 a ed.) (pp. 9-29). Petrópolis, RJ: Vozes.

Parkes, C. M. (1998). Luto: Estudos sobre a perda na vida adulta. (M. H. F. Bromberg, Trad.). São Paulo: Sumus.

Peres, R. S., \& Santos, M. A. (2009). Personalidade e câncer de mama: produção científica em Psico-Oncologia. Psicologia: Teoria e Pesquisa, 25(4), 611-620.

Raveis, V. H., \& Pretter, S. (2005). Existential plight of adult daughters following their mother's breast cancer diagnosis. Psycho-Oncology. 14(1), 49-60.

Rzeznik, C., \& Dall'Agnol, C. M. (2000). (Re)descobrindo a vida apesar do câncer. Revista Gaúcha de Enfermagem, 21 (n. esp.), 84-100.

Schmid-Büchi, S., Halfens, R. J. G., Dassen, T., \& Van den Borne, B. (2008). A review of psychosocial needs of breast-cancer patients and their relatives. Journal of Clinical Nursing, 17(21), 2895-2909. 
Scorsolini-Comin, F., Santos, M. A., \& Souza, L. V. (2009). Vivências e discursos de mulheres mastectomizadas: negociações e desafios do câncer de mama. Estudos de Psicologia (Natal), 14(1), 41-50. Retrieved from http://www. scielo.br/pdf/epsic/v14n1/ a06v14n1.pdf.

Scorsolini-Comin, F., Souza, L. V., \& Santos, M. A. (2008). Tornarse psicólogo: experiência de estágio de Psico-oncologia em equipe multiprofissional de saúde. Revista Brasileira de Orientação Profissional, 9(2), 113-125.

Silva, G., \& Santos, M. A. (2008). “Será que não vai acabar nunca?”: perscrutando o universo do pós-tratamento do câncer de mama. Texto \& Contexto Enfermagem, 17(3), 561-568.

Silva, G., \& Santos, M. A. (2010). Stressors in breast cancer posttreatment: a qualitative approach. Revista Latino-Americana de Enfermagem, 18(4), 688-695.

Sinding, C. (2003). Because you know there's an end to it: caring for a relative or friend with advanced breast cancer. Palliative $\&$ Supportive Care, 1(2), 153-163.

Souza, M. G. G., \& Espírito Santo, F. H. E. (2008). O olhar que olha o outro... um estudo com familiares de pessoas em quimioterapia antineoplásica. Revista Brasileira de Cancerologia; 54(1), 31-41.

Stolagli, V. P., Evangelista, M. R. B., \& Camargo, O. P. (2008). Implicações sociais enfrentadas pelas famílias que possuem pacientes com sarcoma ósseo. Acta Ortopédica Brasileira, 16(4), 242-246.
Tavares, J. S. C., \& Trad, L. A. B. (2005). Metáforas e significados do câncer de mama na perspectiva de cinco famílias afetadas. Cadernos de Saúde Pública, 21(2), 426-435.

Trincaus, M. R., \& Côrrea, A. K. (2007). A dualidade vida-morte na vivência dos pacientes com metástase. Revista da Escola de Enfermagem USP, 41(1), 44-51.

Valle, E. R. M. (1997). Um estudo das pesquisas psicológicas na abordagem fenomenológica sobre o câncer infantil. In E. R. M. Valle (Ed.), Câncer infantil: Compreender e agir (pp. 67-178). Campinas: Editorial Psy.

Waidman, M. A. P., \& Elsen, I. (2004). Família e necessidades... revendo estudos. Psicologia em Estudo, 26(1), 147-157.

Westman, B., Bergenmar, M., \& Andersson, L. (2006). Life, illness and death-existential reflections of a Swedish sample of patients who have undergone curative treatment for breast or prostatic cancer. European Journal of Oncology Nursing, 10(3), 169-176.
Recebido em 03.06.2009

Primeira decisão editorial em 07.06.2011

Versão final em 29.06.2011

Aceito em 14.07.2011 